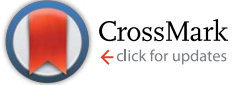

Cite this: RSC Adv., 2016, 6, 71151

Received 15th July 2016 Accepted 19th July 2016

DOI: 10.1039/c6ra18073f

www.rsc.org/advances

\section{Synthesis, structure and photochromic properties of hybrid molecules based on fullerene $\mathrm{C}_{60}$ and spiropyrans $\uparrow$}

\author{
A. R. Tuktarov, ${ }^{\star a}$ A. A. Khuzin, ${ }^{a}$ A. R. Tulyabaev, ${ }^{a}$ O. V. Venidictova, ${ }^{b}$ T. M. Valova, ${ }^{b}$ \\ V. A. Barachevsky, ${ }^{b}$ L. M. Khalilov ${ }^{a}$ and U. M. Dzhemilev ${ }^{a}$
}

The 1,3-dipolar cycloaddition of azomethine ylides to fullerene $C_{60}$ was utilized to perform the synthesis of spiropyran-containing photochromic pyrrolidinofullerenes. It was found that photochromism is observed only for the hybrid compound containing an $\mathrm{NO}_{2}$ group in the pyran moiety, whereas the pyrrolidinofullerenes with $\mathrm{Cl}$ or $\mathrm{F}$ atoms in the spiropyran moiety do not possess photochromism. The photochromic fullerene hybrid is characterized by lower light sensitivity and photodegradation parameters compared to the initial spiropyrans, which can be attributed to reabsorption of activating radiation.

\section{Introduction}

Synthesis of novel organic and organometallic photochromic molecules that undergo reversible photoisomerization is one of the major areas of focus in modern chemistry. Huge interest in such photochromic compounds is driven by the possibility of development of memory elements, ${ }^{1}$ optoelectronic devices, ${ }^{2}$ sensors ${ }^{3}$ etc. based on them.

Among the most popular and extensively studied photochromic molecules are diarylethenes, spiropyrans and spirooxazines, fulgides, as well as azobenzene. The isomeric forms of these compounds differ substantially in their physical and optical properties, ${ }^{4}$ which led to the appearance of a great number of investigations concerning their applications as dynamic materials. ${ }^{5}$ Of specific importance in this research area are studies devoted to the creation of nanomaterials with controlled properties, in particular, light sensitizing of carbon nanomolecules: fullerenes, nanotubes, and graphene. ${ }^{6}$ Investigations of covalent and molecular binding of such carbon clusters to dithienylethenes, ${ }^{7}$ spirooxazines ${ }^{8}$ and azobenzene ${ }^{9}$ have been reported, which made it possible to obtain

${ }^{a}$ Institute of Petrochemistry and Catalysis, Russian Academy of Sciences, Russian Federation. E-mail: tuktarovar@gmail.com

${ }^{b}$ Photochemistry Centre, Russian Academy of Sciences, Russian Federation

$\dagger$ Electronic supplementary information (ESI) available. See DOI: $10.1039 / \mathrm{c} 6 \mathrm{ra18073f}$ conceptually new materials for various fields of science and technology.

One possible way to use such hybrid materials is design of various sensors. These devices employ the modification of the electronic properties of hybrid molecule. It was earlier shown, ${ }^{8 a}$ for example, that spiropyran attached to fullerene $\mathrm{C}_{60}$ via covalent binding can exhibit allochroic properties in polar solvents and in acid or alkali media as well. In the present paper, we demonstrate that the electronic characteristics of hybrid molecules based on [60]fullerene and spiropyrane can also be tailored by light.

Considering the foregoing and also aiming to extend the class of photochromic carbon clusters and to study the influence of the fullerene cage and the photochromic moiety on the electronic properties and stability of the new hybrid molecule, we performed covalent binding of $\mathrm{C}_{60}$ to spiropyrans.

\section{Result and discussion}

The well known reaction of fullerene $\mathrm{C}_{60}$ with in situ generated azomethine ylides (Prato reaction), ${ }^{10}$ which makes it possible to obtain pyrrolidinofullerenes in preparative yields, was used as the basis for the development method.

The experiments showed that the reaction between fullerene $\mathrm{C}_{60}$ and spiropyran 1, which contains an aldehyde and a nitro group in the molecule, in the presence of sarcosine leads to the formation of fulleropyrrolidine 4 in $\sim 60 \%$ yield (Scheme 1). Hybrid compounds 5 and $\mathbf{6}$ were obtained in a similar way.

Compounds 4-6 were isolated from the reaction mixture by column chromatography $\left(\mathrm{SiO}_{2}\right)$. Elution with toluene recovered the unreacted $\mathrm{C}_{60}$, and after that, the use of pyridine as the eluent afforded the target adducts 4-6 with $\sim 100 \%$ purity. The structures of pure fulleropyrrolidines 4-6 were reliably determined by one- $\left({ }^{1} \mathrm{H}\right.$ and $\left.{ }^{13} \mathrm{C}\right)$ and two-dimensional $(\mathrm{H}-\mathrm{H}$ COSY, HSQC, and HMBC) NMR spectroscopy and MALDI TOF/TOF mass spectrometry.

The pyrrolidine moiety of hybrid molecules 4-6 is responsible for ${ }^{13} \mathrm{C}$ NMR signals at $\delta_{\mathrm{C}} 70.11$ (C5), 83.82 (C2), and 40.12 

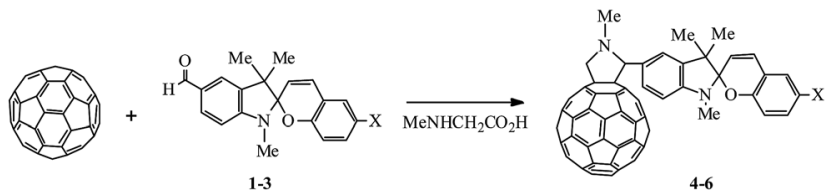

1,4: $\mathrm{X}=\mathrm{NO}_{2} ; 2,5: \mathrm{X}=\mathrm{Cl} ; 3,6: \mathrm{X}=\mathrm{F}$

Scheme 1 Synthesis of spiropyran-containing photochromic pyrrolidinofullerenes.

$\left(\mathrm{N}-\mathrm{CH}_{3}\right)$ correlated in the HSQC experiment with proton signals at $\delta_{\mathrm{H}} 4.29\left(\mathrm{H}_{\mathrm{A}}-\mathrm{C} 5\right), 4.99\left(\mathrm{H}_{\mathrm{B}}-\mathrm{C} 5\right), 4.92(\mathrm{H}-\mathrm{C} 2)$, and $2.91\left(\mathrm{~N}-\mathrm{CH}_{3}\right)$ ppm, respectively. Furthermore, according to HMBC data, five quaternary carbon atoms of the spiro-oxazine moiety incorporated in aromatic rings give rise to the signals at $\delta$ 135.96, $141.13,147.77,153.62$, and 159.47 , located in the same region as the signals characteristic of the $\mathrm{sp}^{2}$-hybridized carbon atoms of the fullerene cage (Fig. 1). Therefore, the ${ }^{13} \mathrm{C}$ NMR spectrum of spiro-oxazine derivative 4 exhibits 48 signals of the $\mathrm{sp}^{2}$ hybridized carbon atoms of the fullerene cage, indicating the $C_{1}$ point group of symmetry for this molecule.

This signal splitting is likely to be caused by the effect of the chiral carbon atom of the pyrrolidine ring, which was observed in our previous studies for fullerene derivatives containing chiral centers in the attached moieties. ${ }^{11}$ No influence of the second chiral carbon atom involved into the spiropyran moiety was revealed because it locates by seven chemical bonds away from the fullerene core. ${ }^{12}$ According to quantum chemical calculations by the GIAO method at the X3LYP/6-31G level of theory, ${ }^{13}$ the high-frequency split signals at $\delta 156.45,156.50$, 154.06, and 154.23 refer to $\mathrm{C} 2, \mathrm{C} 5, \mathrm{C} 8$, and $\mathrm{C} 10$ atoms of the fullerene cage, respectively. It is noteworthy that the C2 and C5 atoms occurring in the $\mathrm{sp}^{2}$-hybridized state are linked to the $\mathrm{sp}^{3}$-hybridized $\mathrm{C} 1$ atom of the fullerene cage and, similarly, C8 and $\mathrm{C} 10$ atoms are linked to $\mathrm{C} 9$, thus forming so-called $\alpha$-environment of $\mathrm{C} 1$ and C9. In turn, the $\beta$-environment for

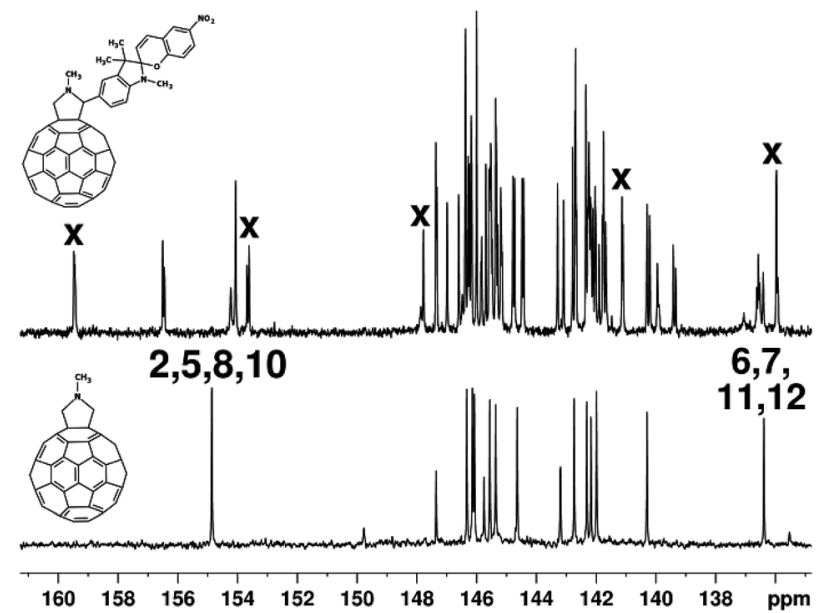

Fig. $1{ }^{13} \mathrm{C}$ NMR spectra of spiro-oxazine adduct 4 (above) and simplest pyrrolidinofullerene (below). The crosses mark the carbon signals of the attached moiety. The digits above the signals mean the numbers of fullerene carbon atoms. the same $\mathrm{sp}^{3}$ atoms is formed by $\mathrm{C} 6, \mathrm{C} 7, \mathrm{C} 11$, and $\mathrm{C} 12$ atoms, which are responsible for low-frequency signals at $\delta 136.41$, 136.52, 136.57, and 136.62, respectively. This observation supports the previously formulated regularity, stating that the $\mathrm{sp}^{2}$ carbon atoms of the fullerene sphere producing the most low-frequency signals are linked to those responsible for highfrequency resonance signals. ${ }^{14}$ Simultaneously, the degree of influence of the chiral carbon atom located in the pyrrolidine ring of the attached moiety can be estimated from the diastereotopic splitting of the signals of carbon atoms located symmetrically relative to each other in the fullerene cage. This can be done by comparing the ${ }^{13} \mathrm{C}$ NMR spectrum of spirooxazine adduct 4 with that of 2,5-unsubstituted pyrrolidinofullerene, which corresponds to the $C_{2 \mathrm{~V}}$ point group of symmetry (Fig. 1 and 2).

The pair signals at $\delta 139.34$ and 139.42 , as well as 140.21 and 140.29 with $1 \mathrm{C}$ intensity in the spectrum of compound 4 merge to form a single signal of $4 \mathrm{C}$ intensity in the spectrum of 2,5unsubstituted pyrrolidinofullerene devoid of the chiral center; this signal refers to four magnetically equivalent and symmetrically located $\mathrm{C} 15, \mathrm{C} 18, \mathrm{C} 24$, and $\mathrm{C} 27$ carbon atoms. The diastereotopic splitting $\Delta \delta_{\text {dias }}$ is calculated as the difference between the chemical shifts of the pair signals $\Delta \delta_{\text {dias }}(\mathrm{C} 15, \mathrm{C} 18)$ $=139.42-139.34 \mathrm{ppm}=0.08 \mathrm{ppm}$ and $\Delta \delta_{\text {dias }}(\mathrm{C} 24, \mathrm{C} 27)=$ 140.29-140.21 ppm $=0.08 \mathrm{ppm}$. The diastereotopic splittings for other carbon atoms were determined in a similar way (Fig. 2).

The structures of the synthesized fulleropyrrolidines 4-6 were also determined with good reliability with MALDI TOF/ TOF mass spectrometry, the spectra being characterized by intensive $[\mathrm{M}-3 \mathrm{H}]$ molecular ion peaks with $\mathrm{m} / \mathrm{z}$ 1096.1, 1085.1, and 1069.1 respectively.

The results of the studies of photochromic properties for compounds 4-6 are summarized in Table 1 (see ESI $\dagger$ ).

Fig. 3 (inset) shows the photoinduced spectral changes of the initial $\mathrm{NO}_{2}$-containing spiropyran 1 in toluene. It can be seen

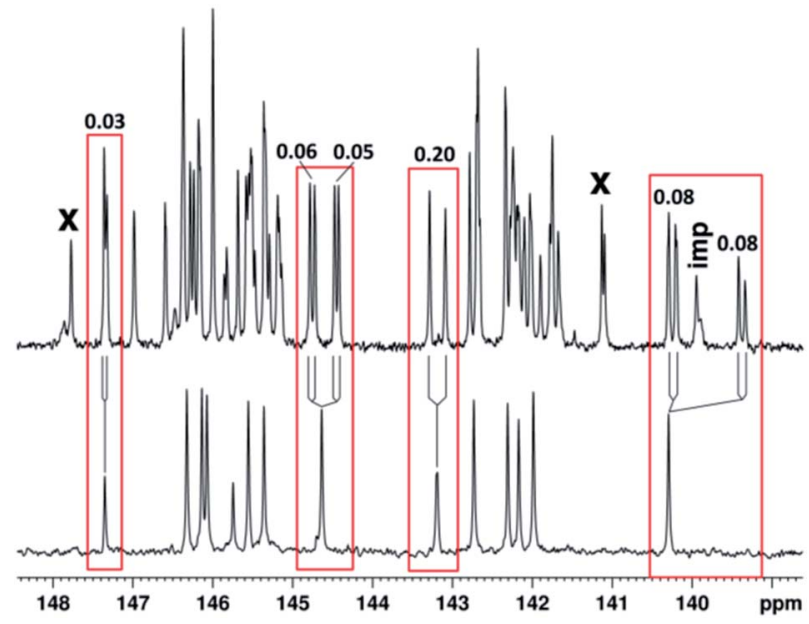

Fig. 2 Extended regions of the ${ }^{13} \mathrm{C}$ NMR spectra of spiro-oxazine adduct 1 (above) and simple pyrrolidinofullerene (below). The crosses mark the carbon signals of the attached moiety. The numerals above the signals imply diastereotopic splitting $\Delta \delta_{\text {dais }}$ 


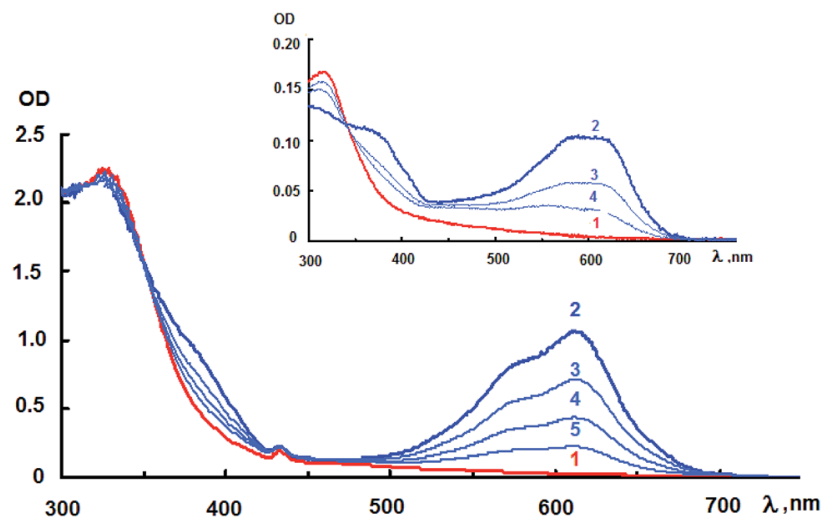

Fig. 3 Absorption spectra of pyrrolidinofullerene 4 in toluene before (1), after UV irradiation during $30 \mathrm{~s}$ through a UFS-1 optical filter in the photoequilibrium state (2), and subsequent dark bleaching $(3,4,5)$. The absorption spectra of the initial spiropyran 1 before (1) and after UV irradiation through a UFS-1 optical filter in the photoequilibrium state (2) and subsequent dark bleaching $(3,4)$ are presented in the inset.

that the absorption spectrum of the photoinduced merocyanine form has two absorption maxima in the visible region at 580 and $620 \mathrm{~nm}$. During the dark relaxation process, the intensity of photoinduced absorption bands gradually decreases. Similar photoinduced spectral changes are also observed for the hybrid compound $\mathbf{4}$ in toluene. In this case, the long-wavelength absorption maximum was more clear-cut and located at 610 nm.

The decline in the amplitude of variation of the absorption band intensity of the photoinduced merocyanine form of spiropyran in hybrid $\mathbf{4}$ also indicates that this compound is subject to photochromic transformations accompanied by a gradual photodegradation (Fig. 4). It should also be noted that no special study to establish influence of molecular oxygen on fatigue resistance and photodegradation of the photochromic compound 4 was carried out, so that it will be a purpose of the future works.

It can be concluded from comparison of the curves presented in Fig. 3 that there are no significant spectral distinctions between the nitro-substituted spiropyran 1 and its hybrid compound with fullerene $\mathbf{4}$, which is presumably indicative of weak interaction between the spiropyran and fullerene

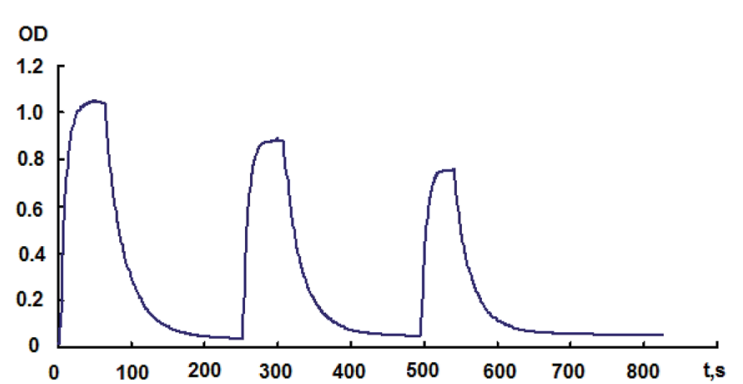

Fig. 4 Kinetics of coloration through a UFS-1 optical filter and subsequent bleaching in the dark for pyrrolidinofullerene 4 dissolved in toluene measured at $610 \mathrm{~nm}$. The measurements were performed in an aerated solution. moieties. There is a difference in the light-sensitivity, which is determined by $\Delta \mathrm{OD}_{\mathrm{B}}^{\text {phot }} / \mathrm{OD}_{\mathrm{A}}^{\max }$ ratio (Table 1 , $\mathrm{ESI} \dagger$ ). This ratio represents the photoinduced change in the optical density at the absorption maximum of the merocyanine form normalized to the maximum intensity of the absorption band of the initial spiran form, which absorbs the activating radiation. The lightsensitivity of hybrid compound $\mathbf{4}$ is lower in both toluene and chloroform compared to the initial spiropyran 1 (Table 1, ESI $\dagger$ ). Substantial difference in the photodegradation of these compounds is observed (Fig. 5). Pyrrolidinofullerene 4 was found to be more resistant to irreversible phototransformations. The photodegradation of compound 4 decreases going from a toluene to a chloroform solution. The decrease in the light-sensitivity and enhancement of the photodegradation resistance of compound $\mathbf{4}$ can be attributed to the reabsorption of the activating radiation by the fullerene moiety, which is located in the absorption area of the photochromic fragment.

The influence of the fullerene moiety in the hybrid photochromic compound $\mathbf{4}$ is manifested as a decrease in the rate of spontaneous dark bleaching of the merocyanine form in both toluene and chloroform (Table 1, ESI $\dagger$ ). This may serve as evidence for covalent bonding between the spiropyran molecule and the fullerene moiety.

Photochromic transformations of the initial spiropyran 1 and pyrrolidinofullerene $\mathbf{4}$ were also found for amorphous films (Fig. 4, Table 1 in ESI $\dagger$ ).

Unfortunately, unlike photochromic compounds 2 and 3 pyrrolidinofullerenes 5 and $\mathbf{6}$ do not exhibit photochromic transformations upon either constant or pulsed photoexcitation. This is not related to quick spontaneous dark relaxation of the photoinduced form, because compound $\mathbf{4}$ is characterized by lower bleaching rate compared to the initial photochromic compound 1. Reabsorption of the activating light by the fullerene moiety may serve as a possible explanation, as in pyrrolidinofullerenes 5 and $\mathbf{6}$, the absorption bands of the spiran forms of the initial compounds 2 and 3 effectively overlap with the fullerene absorption spectrum (see ESI $\dagger$ ). In the case of the initial spiropyran $\mathbf{1}$, only partial overlap of the spectra is

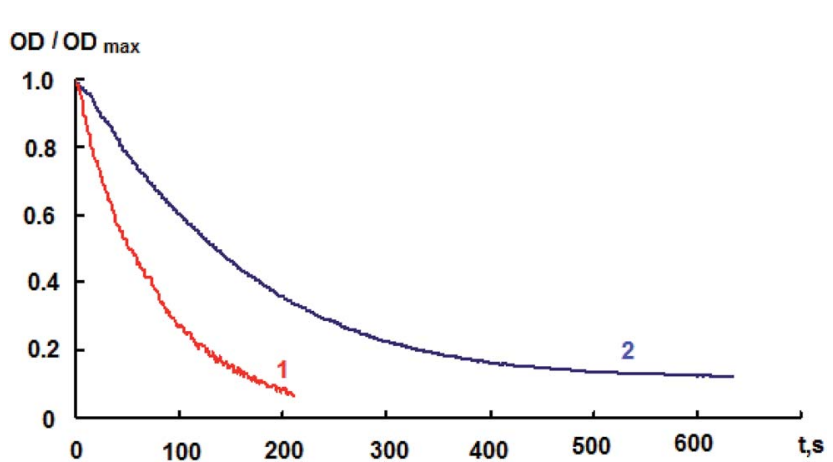

Fig. 5 Normalized kinetic curves of photodegradation of the initial spiropyran 1 (1) and pyrrolidinofullerene 4 (2) in toluene at the presence of air oxygen. The measurements were performed at the absorption maximum of photoinduced merocyanine forms $(610 \mathrm{~nm})$ irradiated through the UFS-1 optical filter. 
observed for pyrrolidinofullerene 4, making it possible to witness photochromic transformations of the hybrid molecule 4. Another possible explanation for decreasing light-sensitivity of compound $\mathbf{4}$ and the lack of photochromism of pyrrolidinofullerenes 5 and $\mathbf{6}$ is the photo-induced electron transfer from the photochromic fragment to electron accepter fullerene moiety.

\section{Conclusions}

Thus, we accomplished for the first time the covalent binding of photochromic spiropyrans to fullerene $\mathrm{C}_{60}$ and thus obtained novel hybrid molecules, characterized by photochromism and substantial resistance to irreversible phototransformations, unlike the initial substrates. This opens up prospects for the application of such hybrid molecules in organic field effect transistors, solar energy converters, and memory elements.

\section{Acknowledgements}

This work was financially supported by a grant of the Russian Science Foundation (No. 14-13-00296).

\section{Notes and references}

1 (a) H. Bouas-Laurent and H. Dürr, Pure Appl. Chem., 2001, 73, 639; (b) E. Orgiu and P. Samori, Adv. Mater., 2014, 26, 1827.

2 M. Tomasulo, I. Yildiz and F. M. Raymo, Inorg. Chim. Acta, 2007, 360, 938.

3 (a) K. Kimura, Coord. Chem. Rev., 1996, 148, 41; (b) I. Willner, Acc. Chem. Res., 1997, 30, 347; (c) L. Evans, G. E. Collins, R. E. Shaffer, V. Mechelet and J. D. Winkler, Anal. Chem., 1999, 71, 5322; (d) B. Valeur and I. Leray, Coord. Chem. Rev., 2000, 205, 3; (e) V. A. Bren, Russ. Chem. Rev., 2001, 70, 1152; (f) X. Xie, G. Mistlberger and E. Bakker, J. Am. Chem. Soc., 2012, 134, 16929; $(g)$ M. Qin, Y. Huang, F. Li and Y. Song, J. Mater. Chem. C, 2015, 3, 9265; (h) E. N. Shepelenko, Y. V. Revinskii, K. S. Tikhomirova, O. G. Karamov, A. D. Dubonosov, V. A. Bren and V. I. Minkin, Mendeleev Commun., 2016, 26, 193.

4 (a) V. I. Minkin, Chem. Rev., 2004, 104, 2751; (b) M. M. Krayushkin, A. M. Bogacheva, K. S. Levchenko, O. I. Kobeleva, T. M. Valova, V. A. Barachevskii, J.-L. Pozzo, M. I. Struchkova, P. S. Shmelin, M. A. Kalik, T. K. Baryshnikova and V. N. Charushin, Mendeleev Commun., 2013, 23, 78.

5 R. Klajn, Chem. Soc. Rev., 2014, 43, 148.

6 X. Zhang, L. Hou and P. Samori, Nat. Commun., 2016, 7, 11118.

7 (a) P. A. Liddell, G. Kodis, A. L. Moore, T. A. Moore and D. Gust, J. Am. Chem. Soc., 2002, 124, 7668; (b) H.-Y. Hu, M.-Z. Zhu, Z.-P. Zhang, G.-T. Wen, Y. Fu and Q.-X. Guo, Chin. J. Chem. Phys., 2006, 19, 433; (c) A. C. Whalley, M. L. Steigerwald, X. Guo and C. Nuckolls, J. Am. Chem. Soc., 2007, 129, 12590; (d) C. Motta, M. I. Trioni, G. P. Brivio and K. L. Sebastian, Phys. Rev. B: Condens. Matter Mater. Phys., 2011, 84, 113408; (e) S. Castellanos,
A. A. Vieira, B. M. Illescas, V. Sacchetti, C. Schubert, J. Moreno, D. M. Guldi, S. Hecht and N. Martin, Angew. Chem., Int. Ed., 2013, 52, 13985; (f) A. R. Tuktarov, A. A. Khuzin, A. R. Akhmetov, V. A. Barachevsky, O. V. Venidiktova and U. M. Dzhemilev, Tetrahedron Lett., 2015, 56, 7154; (g) A. R. Tuktarov, A. A. Khuzin, A. R. Akhmetov, L. M. Khalilov, A. R. Tulyabaev, V. A. Barachevsky, O. V. Venidiktova and U. M. Dzhemilev, Mendeleev Commun., 2016, 26, 143.

8 (a) J.-H. Xu, Y.-L. Li and D.-B. Zhu, Synth. Commun., 2002, 32, 1647; (b) X. Guo, L. Huang, S. O'Brien, P. Kim and C. Nuckollls, J. Am. Chem. Soc., 2005, 127, 15045; (c) E. Del Canto, K. Flavin, M. Natali, T. Perova and S. Giordani, Carbon, 2010, 48, 2815; (d) P. Joo, B. J. Kim, E. K. Jeon, J. H. Cho and B.-S. Kim, Chem. Commun., 2012, 48, 10978; (e) A.-R. Jang, E. K. Jeon, D. Kang, G. Kim, B.-S. Kim, D. J. Kang and H. S. Shin, ACS Nano, 2012, 6, 9207; $(f)$ J. Frey, G. Kodis, S. D. Straight, T. A. Moore, A. L. Moore and D. Gust, J. Phys. Chem. A, 2013, 117, 607; $(g)$ A.-A. Nahain, J.-E. Lee, J. H. Jeong and S. Y. Park, Biomacromolecules, 2013, 14, 4082; $(h)$ Y. Li, Y. Duan, J. Zheng, J. Li, W. Zhao, S. Yang and R. Yang, Anal. Chem., 2013, 85, 11456; (i) S. M. Sharker, C. J. Jeong, S. M. Kim, J.-E. Lee, J. H. Jeong, I. In, H. Lee and S. Y. Park, Chem.Asian J., 2014, 9, 2921; (j) A. Perry, S. J. Green, D. W. Horsell, S. M. Hornett and M. E. Wood, Tetrahedron, 2015, 71, 6776.

9 (a) K. Oh-ishi, J. Okamura, T. Ishi-i, M. Sano and S. Shinkai, Langmuir, 1999, 15, 2224; (b) K.-Y. Kay, K.-J. Han, Y.-J. Yua and Y. D. Park, Tetrahedron Lett., 2002, 43, 5053; (c) Y. Yang, X. Wang, L. Liu, X. Xie, Z. Yang, R. K. Y. Li and Y.-W. Mai, J. Phys. Chem. C, 2007, 111, 11231; (d) J. M. Simmons, I. In, V. E. Campbell, T. J. Mark, F. Leonard, P. Gopalan and M. A. Eriksson, Phys. Rev. Lett., 2007, 98, 086802; (e) Y. Feng, X. Zhang, X. Ding and W. Feng, Carbon, 2010, 48, 3091; (f) Y. Cao, S. Dong, S. Liu, Z. Liu and X. Guo, Angew. Chem., Int. Ed., 2013, 52, 3906; (g) K. Yuan, Y.-J. Guo and X. Zhao, Phys. Chem. Chem. Phys., 2014, 16, 27053; (h) S. Ma, H. Ting, L. Zhang, Y. Ma, L. Zheng, L. Xiao and Z. Chen, Org. Electron., 2015, 23, 1; (i) W. Luo, Y. Feng, C. Cao, M. Li, E. Liu, S. Li, C. Qin, W. Hu and W. Feng, J. Mater. Chem. A, 2015, 3, 11787; (j) W. Luo, Y. Feng, C. Qin, M. Li, S. Li, C. Cao, P. Long, E. Liu, W. Hu, K. Yoshino and W. Feng, Nanoscale, 2015, 7, 16214.

10 M. Maggini, G. Scorrano and M. Prato, J. Am. Chem. Soc., 1993, 115, 9798.

11 (a) L. M. Khalilov, A. R. Tulyabaev and A. R. Tuktarov, Magn. Reson. Chem., 2011, 49, 768; (b) A. R. Tulyabaev, A. R. Tuktarov and L. M. Khalilov, Magn. Reson. Chem., 2014, 52, 3.

12 J. I. Kroschwitz, M. Winokur, H. J. Reich and J. D. Roberts, J. Am. Chem. Soc., 1969, 91, 5927.

13 M. J. Frisch, G. W. Trucks, H. B. Schlegel, G. E. Scuseria, M. A. Robb, J. R. Cheeseman, G. Scalmani, V. Barone, B. Mennucci, G. A. Petersson, H. Nakatsuji, M. Caricato, X. Li, H. P. Hratchian, A. F. Izmaylov, J. Bloino, G. Zheng, 
J. L. Sonnenberg, M. Hada, M. Ehara, K. Toyota, R. Fukuda, J. Hasegawa, M. Ishida, T. Nakajima, Y. Honda, O. Kitao, H. Nakai, T. Vreven, J. A. Montgomery Jr, J. E. Peralta, F. Ogliaro, M. Bearpark, J. J. Heyd, E. Brothers, K. N. Kudin, V. N. Staroverov, R. Kobayashi, J. Normand, K. Raghavachari, A. Rendell, J. C. Burant, S. S. Iyengar, J. Tomasi, M. Cossi, N. Rega, J. M. Millam, M. Klene, J. E. Knox, J. B. Cross, V. Bakken, C. Adamo, J. Jaramillo, R. Gomperts, R. E. Stratmann, O. Yazyev, A. J. Austin, R. Cammi, C. Pomelli, J. W. Ochterski, R. L. Martin,
K. Morokuma, V. G. Zakrzewski, G. A. Voth, P. Salvador, J. J. Dannenberg, S. Dapprich, A. D. Daniels, Ö. Farkas, J. B. Foresman, J. V. Ortiz, J. Cioslowski and D. J. Fox, Gaussian 09, Revision E.01, Gaussian, Inc., Wallingford CT, 2009.

14 (a) M. S. Meier, H. P. Spielmann, R. G. Bergosh and R. C. Haddon, J. Am. Chem. Soc., 2002, 124, 8090; (b) M. S. Meier, H. P. Spielmann, R. G. Bergosh and M. C. Tetreau, J. Org. Chem., 2003, 68, 7867. 